\title{
A tradição filosófica e o eurocentrismo: como decolonializar o filosofar e o ensino de Filosofia contemporâneo?
}

\author{
The philosophical tradition and Euroscentrism: how to decolonialize the philosopher \\ and the contemporary teaching of Philosophy?
}

\author{
Amanda Veloso Garcia \\ Doutoranda na Universidade Estadual Paulista Júlio de Mesquita Filho, Marília, São Paulo, Brasil. \\ amanda.garcia@ifrj.edu.br - https://orcid.org/0000-0002-4959-8256
}

Recebido em 24 de janeiro de 2020

Aprovado em 06 de agosto de 2020

Publicado em 24 de setembro de 2020

\section{RESUMO}

A história da Filosofia ocidental dominante contribuiu fortemente para a colonização e para o delineamento de processos racistas através do estabelecimento de hierarquias baseadas no conceito de razão eurocêntrico. Entre as ideologias com maior impacto na colonialidade podermos citar o dualismo eurocêntrico que separa corpo e razão e o mito da existência de um estado de natureza. Nesse sentido, a Filosofia tem grande responsabilidade na colonialidade e acreditamos que seu ensino tem como obrigação descontruir tais ideologias. Diante disso, nesse artigo temos como objetivo evidenciar os pressupostos eurocêntricos da Filosofia a fim de pensar um ensino decolonial e que esteja à altura dos problemas contemporâneos, em geral causados pela própria lógica ocidental. Defenderemos que um ensino de Filosofia decolonial precisa romper com as hierarquias eurocêntricas e valorizar a experiência como forma de conhecimento. Palavras-chave: Colonialidade; Dualismo; Currículo; Problemas; Experiência.

\section{ABSTRACT}

The history of dominant Western Philosophy contributed strongly to the colonization and racist processes by establishing hierarchies based on the concept of Eurocentric reason. Among the ideologies with the greatest impact on coloniality we can cite the Eurocentric dualism that separates body and reason and the myth of the existence of a state of nature. In this sense. Philosophy has great responsibility in coloniality and we believe that its teaching has as an obligation to unwind such ideologies. In view of this article, we aim to highlight the Eurocentric assumptions of Philosophy in order to think about a decolonial teaching and that is corresponds to contemporary problems, usually caused by Western logic itself. We will argue that a decolonial teaching of Philosophy needs to break with eurocentric hierarchies and value experience as a form of knowledge. Keywords: Coloniality; Dualism; Curriculum; Problems; Experience.

\section{Introdução}

A história da Filosofia Ocidental hegemônica ${ }^{1}$ tem profunda ligação com os processos de dominação política. Basta observar que filósofos de grande destaque tiveram participação 
importante em concepções racistas e sexistas no decorrer da história. A Filosofia Ocidental hegemônica tem grande responsabilidade na colonialidade e nos mitos modernos, e, por isso, o ensino de Filosofia tem o dever de refletir profundamente sobre tais concepções e colaborar na sua desconstrução. Diante disso, temos como objetivo nesse artigo evidenciar os pressupostos eurocêntricos da Filosofia a fim de pensar um ensino decolonial e que esteja à altura dos problemas contemporâneos, em geral causados pela própria lógica ocidental.

Os pressupostos eurocêntricos da Filosofia Ocidental hegemônica invisibilizam alguns saberes enquanto pregam outros como verdades absolutas. O pensamento dominante submete a hierarquias todas as facetas da vida com o objetivo de exercer controle sobre a população, a Filosofia ocidental serviu a esses interesses em vários momentos da história conscientemente ou inconscientemente. Para discutir tal hierarquização do pensamento e da vida, inicialmente traremos as contribuições de Anibal Quijano (1992, 2005) apontando para o dualismo eurocêntrico - que aprofundaremos a partir da árvore do conhecimento de Descartes - como importante elemento de dominação. Por fim, pretendemos refletir sobre como o ensino de Filosofia no Brasil pode se decolonializar promovendo um pensamento mais significativo para os desafios contemporâneos.

\section{A contribuição da Filosofia para os mitos da colonialidade}

Desde a Antiguidade Ocidental estavam presentes alguns valores que serviriam de base para o eurofalogocentrismo (DERRIDA, 1991), isto é, a crença na superioridade de um padrão europeu patriarcal e baseado na razão - logos -. Entre os elementos mais importantes da ideologia eurofalogocêntrica está o dualismo. Para Aníbal Quijano (1992, 2005), o dualismo mente/corpo eurocêntrico contribuiu fortemente para as classificações de raça e gênero. Embora a diferenciação entre corpo e não-corpo esteja presente desde muito tempo, apenas com o surgimento do eurocentrismo esta vai ser delineada como separação, sem a ideia de copresença que aparecia em outros períodos ou culturas.

$\mathrm{Na}$ Grécia Antiga, por exemplo, eram considerados livres apenas aqueles que não estavam subordinados às necessidades vitais, isto é, que não estavam voltados às preocupações com a conservação de sua vida. Não havia liberdade na vida privada por ser considerado o espaço da necessidade e as pessoas que se dedicavam às tarefas domésticas não tinham direito à cidadania nem à liberdade que eram exercidas no espaço da pólis. Por tais aspectos que as mulheres não eram consideradas cidadãs. Isso também foi reafirmado a partir da ideia recorrente de que o "homem" livre é aquele que consegue dominar e controlar seus sentimentos e pensamentos, o que aparece em filósofos como Sócrates, Platão e Aristóteles. Se a própria natureza do ser humano passa a ser definida a partir da racionalidade, o que nessa visão não é compartilhado por nenhum outro ser, a vocação e realização do homem só pode ocorrer a partir do exercício do uso da razão. Com o passar dos séculos o corpo vai se afastando cada vez mais do universo da racionalidade. Com a cultura repressiva do cristianismo o corpo fica restrito ao universo do pecado e a razão se torna o instrumento para controlá-lo. 
A cisão mente/corpo foi sistematicamente teorizada e ganhou amplitude ainda maior com Descartes (1596-1650). Como explica Quijano (2005, p. 129),

Com Descartes o que sucede é a mutação da antiga abordagem dualista sobre o "corpo" e o "não-corpo". O que era uma co-presença permanente de ambos os elementos em cada etapa do ser humano, em Descartes se converte numa radical separação entre "razão/sujeito" e "corpo". A razão não é somente uma secularização da idéia de "alma" no sentido teológico, mas uma mutação numa nova id-entidade, a "razão/sujeito", a única entidade capaz de conhecimento "racional", em relação à qual o "corpo" é e não pode ser outra coisa além de "objeto" de conhecimento. Desse ponto de vista o ser humano é, por excelência, um ser dotado de "razão", e esse dom se concebe como localizado exclusivamente na alma. Assim o "corpo", por definição incapaz de raciocinar, não tem nada a ver com a razão/sujeito. Produzida essa separação radical entre "razão/sujeito" e "corpo", as relações entre ambos devem ser vistas unicamente como relações entre a razão/sujeito humana e o corpo/natureza humana, ou entre "espírito" e "natureza". Deste modo, na racionalidade eurocêntrica o "corpo" foi fixado como "objeto" de conhecimento, fora do entorno do "sujeito/razão".

Com o trabalho de Descartes há a afirmação de uma nova id-entidade na qual razão e sujeito se tornam indissociáveis delegando o corpo ao universo da natureza. Desse modo o corpo só pode ser objeto de conhecimento devido sua caracterização como irracional através dos impulsos e instintos. A filosofia cartesiana foi decisiva na história para afirmar a inferioridade do corpo na obtenção do conhecimento. Para ele, as paixões têm o poder de iludir a "alma" com enganações ou ilusões e, por isso, o intelecto seria uma entidade superior que teria o poder de controlar as paixões e, inclusive, é o "Cogito, ergo sum" que permite a afirmação da existência humana de maneira segura. Embora a diferenciação entre corpo e não-corpo esteja presente desde muito tempo, apenas com o eurofalogocentrismo esta vai ser delineada como separação, sem a ideia de copresença que aparecia em outros períodos ou culturas. A grande inovação que o eurofalogocentrismo acrescentou ao dualismo foi tornar o corpo um objeto do conhecimento, fora da id-entidade razão/sujeito, o que justificou a exploração feita em alguns territórios:

Sem essa "objetivização" do "corpo" como "natureza", de sua expulsão do âmbito do "espírito", dificilmente teria sido possível tentar a teorização "científica" do problema da raça, como foi o caso do Conde de Gobineau (1853-1857) durante o século XIX. Dessa perspectiva eurocêntrica, certas raças são condenadas como "inferiores" por não serem sujeitos "racionais". São objetos de estudo, "corpo" em conseqüência, mais próximos da "natureza". Em certo sentido, isto os converte em domináveis e exploráveis. De acordo com o mito do estado de natureza e da cadeia do processo civilizatório que culmina na civilização européia, algumas raças - negros (ou africanos), índios, oliváceos, amarelos (ou asiáticos) e nessa sequência - estão mais próximas da "natureza" que os brancos. (QUIJANO, 2005, p. 129) 
A vinculação entre corpo e natureza leva ao entendimento de que alguns povos que, diferentemente dos europeus, não tinham como prática a repressão de suas experiências, têm suas vidas reduzidas a objetos de exploração europeia. Tal relação serviu de justificativa para o controle sobre alguns povos vistos como "irracionais", já que o conhecimento se torna algo de uma entidade racional superior e abstrata se descolando das experiências cotidianas. Quando mais um povo cultiva saberes corporais e ligados à experiência mais é visto como inferior nesta lógica ignorando que o conhecimento não se produz fora das experiências vividas e que a teorização abstrata não é a única forma de saber que existe. E, nesse sentido, os povos nativos foram considerados "inferiores" principalmente por sua ligação intrínseca com o corpo, que entendido como restrito aos impulsos deveria ser controlado e reprimido pela razão, id-entidade superior do homem.

Dessa maneira, povos de relevantes culturas das Américas foram convertidos em subculturas apenas por não possuírem padrões de expressão formalizados de acordo com os padrões ocidentais dominantes de racionalidade, como se não tivessem modo algum de se expressar (QUIJANO, 1992, p. 13, tradução nossa). Por isso, foi necessário "subvertê-los em certos casos, para transmitir outras necessidades de expressão" (QUIJANO, 1992, p. 13, tradução nossa), além de delineá-los como "exóticos" para deslegitimá-los no âmbito do saber/poder. No desenvolvimento da racionalidade/modernidade muitas experiências valiosas são descartadas simplesmente por não se encaixarem no ideal de racionalidade eurofalogocêntrica, se tornam invisíveis no campo dos saberes. Nesse sentido, há a identificação com corpo com uma ideia restrita de natureza ao mesmo tempo que a racionalidade passa a ser parte fundamental de um padrão restrito de humanidade:

desigualdades são percebidas como da natureza: só a cultura européia
é racional, pode conter "sujeitos". Os outros não são racionais. Eles
não podem ser ou abrigar "sujeitos". Consequentemente, outras
culturas são diferentes no sentido de serem desiguais, de fato
inferiores, por natureza. Eles só podem ser "objetos" de práticas de
conhecimento e/ou dominação. Nesta perspectiva, a relação entre a
cultura européia e outras culturas foi estabelecida e desde então tem
sido mantida como uma relação entre "sujeito" e "objeto". (QUIJANO,
1992, p. 16, tradução nossa)

Nessa perspectiva, se a racionalidade eurofalogocêntrica é entendida como universal, quem não a reproduz não pode ser considerado portador de razão alguma. Logo, não é sujeito, portanto, não tem humanidade. A partir da id-entidade razão/sujeito a perspectiva hegemônica estabelece que a zona colonial é o universo das crenças e dos comportamentos incompreensíveis que não são verdadeiros ou falsos, isto é, não podem ser considerados conhecimento "válido". Os comportamentos dos não europeus servem somente como objeto de análise científica porque, neste contexto, o "selvagem" é visto como um sub-humano que necessita ser educado. Só é reconhecido como sujeito aquele que corresponde ao restrito ideal europeu, o que implica em uma série de outras dualidades: 
Isto deu vazão à peculiar perspectiva histórica dualista/evolucionista. Assim todos os não-europeus puderam ser considerados, de um lado, como pré-europeus e ao mesmo tempo dispostos em certa seqüência histórica e contínua do primitivo ao civilizado, do irracional ao racional, do tradicional ao moderno, do mágico-mítico ao científico. Em outras palavras, do não-europeu/pré-europeu a algo que com o tempo se europeizará ou "modernizará". (QUIJANO, 2005, p. 129)

A ideia de progresso eurofalogocêntrica é resultado de uma "ideia-imagem da história da civilização humana como uma trajetória que parte de um estado de natureza e culmina na Europa" (QUIJANO, 2005, p. 122). Isto se explica pelo "fato de que os europeus ocidentais imaginaram ser a culminação de uma trajetória civilizatória desde um estado de natureza, levou-os também a pensar-se como os modernos da humanidade e de sua história, isto é, como o novo e ao mesmo tempo o mais avançado da espécie" (QUIJANO, 2005, p. 122).

O mito do evolucionismo eurofalogocêntrico é elaborado teoricamente com a ideia da existência de um "estado de natureza" aprofundada pelos filósofos contratualistas como Thomas Hobbes (1588-1679), John Locke (1632-1704) e Jean-Jacques Rousseau (1712-1778). Embora os três autores divirjam em alguns aspectos acerca dos direitos básicos do homem, têm como semelhança a compreensão de que existiu um estado pré-civilizatório que gerou a necessidade de um contrato social com a finalidade de proteger os seres humanos. Enquanto na perspectiva hobbesiana fora do âmbito da sociedade o ser humano seria movido por suas paixões e desejos sendo incapaz de conviver levando a um "estado de guerra de todos contra todos", na teoria rousseauniana o estado de natureza é romantizado a partir do conceito de "bom selvagem". Entretanto, o "bom selvagem" é uma invenção europeia, pois o "estado de natureza é pré-social, e a vida social é inerente à condição humana" (ROUANET, 1999, p. 432), o que torna inconsistente associar os povos originários à tal ideal. O mito do "estado de natureza" consiste em mais uma projeção europeia que só resultou em mais encobrimento:

Se invertermos as virtudes atribuídas aos índios, encontraremos os vícios europeus: rancor, dissimulação, espírito vingativo. Por exemplo, à veracidade dos índios corresponde a duplicidade européia. Assim, segundo Las Casas, quando se perguntava aos índios se eram cristãos, respondiam que já o eram um pouco, porque sabiam mentir um pouco, mas que seriam mais cristãos quando tivessem aprendido a mentir mais. (ROUANET, 1999, p. 423)

Nesse sentido podemos dizer que a imagem do "índio" foi uma invenção europeia a partir da projeção de si mesmos. Podemos entender que a base fundacional da versão eurofalogocêntrica da modernidade são as "ideias mitificadas de progresso e da existência de um estado de natureza na trajetória humana” (QUIJANO, 2005, p. 19) haja vista que reafirmavam uma linearidade evolutiva na história. A modernidade se alicerça no pressuposto de uma "totalidade historicamente homogênea" e linear que entende a todos os povos como "um continuum evolutivo do primitivo ao civilizado, do tradicional ao moderno, 
do selvagem ao racional, do pré-capitalismo ao capitalismo", de maneira que a Europa via a si mesmo como o "espelho do futuro de todas as demais sociedades e culturas; como o modo avançado da história de toda a espécie" (QUIJANO, 1992, p. 18, tradução nossa). Nessa perspectiva, aqueles tidos como o centro do mundo por se autodeclarem os mais desenvolvidos teriam a função de civilizar os demais. Desse modo, diferenças passam a ser entendidas como desigualdades naturais que se expressam especialmente na ideia de "raça" e determinam os que deveriam ser explorados e os que deveriam usufruir dos lucros.

Filósofos renomados como Hume (1711-1776), Kant (1724-1804) e Hegel (1770-1831) também contribuíram para os processos de dominação baseados na raça conforme podemos verificar na seguinte citação de Hume:

\begin{abstract}
Eu estou em condições de suspeitar serem os negros naturalmente inferiores aos brancos. Praticamente não houve nações civilizadas de tal compleição, nem mesmo qualquer indivíduo de destaque, seja em ações seja em investigação teórica. [...] Tal diferença uniforme e constante não poderia ocorrer, em tantos países e épocas, se a natureza não tivesse feito uma distinção original entre essas raças de homens. Sem citar as nossas colônias, há escravos negros dispersos por toda a Europa, dos quais ninguém alguma vez descobriu quaisquer sinais de criatividade, embora pessoas de baixa condição, sem educação, venham a progredir entre nós, e destaquem-se em cada profissão. Na Jamaica, realmente, falam de um negro de posição e estudo, mas provavelmente ele é admirado por realização muito limitada como um papagaio, que fala umas poucas palavras claramente (HUME, 2004, p. 252).
\end{abstract}

Hume afirma que pessoas negras são inferiores devido uma diferença de natureza com relação aos brancos porque ele não conhece nenhum indivíduo negro de destaque e aquele único de quem ouviu falar - jamaicano - deve ser um "papagaio" limitado que não tem consciência do que fala. O autor desconsidera que pessoas escravizadas não têm as mesmas oportunidades e raramente são ouvidas, como poderia qualquer escravizado demonstrar seu conhecimento se sequer podem falar o que pensam? Além do que, Hume considera conhecimento apenas o seu próprio pensamento e realidade, embora seja completamente ignorante dos saberes africanos, para ele, "sabedoria" é apenas sua própria cultura, todo o resto é "ignorância". Hume demonstra não conhecer muitos negros, se baseia no que ouviu falar sem qualquer evidência empírica. Nada mais ignorante que tomar sua própria experiência como universal, aliás, este é um dos principais problemas de entender o conhecimento como uma construção individual e não coletiva. Porque ele nunca ouviu falar quer dizer que não existe nenhum negro com "criatividade". O fato de Hume não conhecer nenhum negro de destaque é resultado de um sistema que escravizava e assassinava, o que nada tinha de natural, mas era totalmente político e baseado na irracionalidade branca-europeia. Kant também concordou com Hume: 
Os negros da África não possuem, por natureza, nenhum sentimento que se eleve acima do ridículo. O senhor Hume desafia qualquer um a citar um único exemplo em que um Negro tenha mostrado talentos, e afirma: dentre os milhões de pretos que foram deportados de seus países, não obstante muitos deles terem sido postos em liberdade, não se encontrou um único sequer que apresentasse algo grandioso na arte ou na ciência, ou em qualquer outra aptidão; já entre os brancos, constantemente arrojam-se aqueles que, saídos da plebe mais baixa, adquirem no mundo certo prestígio, por força de dons excelentes. Tão essencial é a diferença entre essas duas raças humanas, que parece ser tão grande em relação às capacidades mentais quanto à diferença de cores. A religião do fetiche, tão difundida entre eles, talvez seja uma espécie de idolatria, que se aprofunda tanto no ridículo quanto parece possível à natureza humana. A pluma de um pássaro, o chifre de uma vaca, uma concha, ou qualquer outra coisa ordinária, tão logo seja consagrada por algumas palavras, tornam-se objeto de adoração e invocação nos esconjuros. Os negros são muito vaidosos, mas à sua própria maneira, e tão matraqueadores, que se deve dispersá-los a pauladas (KANT, 1993, p. 75-76).

Kant afirma que a cultura e costumes africanos são "ridículos" afirmando baseado em nenhuma evidência - lembrando que Kant sequer saiu da província que vivia - que não existem negros que apresentem "algo grandioso na arte ou na ciência, ou em qualquer outra aptidão". Por outro lado, assim como Hume afirma que existem muitos brancos de destaque, desconsiderando as desigualdades sociais. Kant em nome de uma suposta "razão universal" reafirma o exposto por Hume de maneira ainda mais irracional, inclusive indicando que os negros devem ser "dispersados à pauladas". Ambos os filósofos apresentam afirmações sem base alguma na realidade que apenas apontam para o completo desconhecimento dos mesmos sobre o pensamento africano. Isto é Filosofia? Estranho que muitos questionamentos sejam levantados quando falados de filosofia latino-americana, indígena ou brasileira, mas não se questione igualmente teorias como essas de filósofos renomados.

Tal contexto levou Hegel a afirmar que faltava aos africanos a objetividade e, por isso, não teriam história. Segundo Hegel (1982, p. 279-283), a África: 
Não tem interesse histórico próprio, senão o de que os homens vivem ali na barbárie e na selvageria, sem fornecer nenhum elemento à civilização. Por mais que retrocedamos na história, acharemos que a África está sempre fechada no contato com o resto do mundo, é um Eldorado recolhido em si mesmo, é o país criança, envolvido na escuridão da noite, aquém da luz da história consciente. [...] Nesta parte principal da África, não pode haver em realidade história. Não há mais que casualidade, surpresas, que se sucedem umas às outras. Não há nenhum fim, nenhum Estado, que possa se perseguir; não há nenhuma subjetividade, mas somente uma série de sujeitos que se destroem. [...] Entre os negros é, de fato, característico o feito de que sua consciência não chegou ainda à intuição de nenhuma objetividade, como, por exemplo, Deus, a lei, na qual o homem está em relação com sua vontade e tem a intuição de sua essência. $O$ africano não chegou todavia a essa distinção entre ele mesmo como indivíduo e sua universalidade essencial; é impedido pela sua unidade compacta, indiferenciada, onde não existe o conhecimento de uma ciência absoluta, distinta e superior ao eu. Encontramos, pois, aqui o homem em sua imediatez. [...] encontra-se no primeiro estágio, dominado pela paixão, pelo orgulho e a pobreza; é um homem em estado bruto. [...] O negro representa o homem natural em toda a sua barbárie e violência; para compreendê-lo devemos esquecer todas as representações europeias. Devemos esquecer Deus e a lei moral. Para compreendê-lo exatamente, devemos abstrair de todo respeito e moralidade, de todo o sentimento. Tudo isso está no homem em seu estado imediato, em cujo caráter nada se encontra que pareça humano.

Hegel afirma que o africano é o homem em sua "imediatez" (1982, p. 281), em seu "primeiro estágio" (1982, p. 282), "em estado bruto" (1982, p. 282), “dominado pela paixão" (1982, p. 282), envolto em "barbárie e violência" (1982, p. 283) que em nada se assemelha com um humano; pois, segundo ele, não é capaz de olhar para além da sua experiência subjetiva. Hegel associa a objetividade à Deus, à moralidade, às leis, à "ciência absoluta, distinta e superior ao eu" (1982, p. 281), sem perceber que a realidade africana aponta justamente para o fato de que nada disso possa ser entendido como universal. Ignora também que especialistas em barbárie são os próprios europeus que causaram diversos genocídios e holocaustos ao longo da história. Hegel afirma que a África é um continente sem história, porém, são as relações de poder desiguais que apagam e invisibilizam a história e os saberes dos povos africanos.

O que Hume, Kant e Hegel citam como evidências nada mais são do que etnocentrismo, haja vista que adotam por "criatividade", "arte", "universalidade", "objetividade", "ciência" e "história" aquilo que é desenvolvido pela cultura europeia, impossibilitados pelo dogmatismo - algo que desde a Antiguidade grega é de natureza inversa à Filosofia de experienciar e compreender outros tipos de saberes. No mundo contemporâneo tais afirmações se tornam ainda mais incabíveis se considerarmos que grande parte da arte considerada sofisticada, especialmente na música, tem origem na cultura africana, tais como o jazz, blues, samba, bossa nova, etc. Sem qualquer embasamento que não seja o preconceito, tais escritos foram replicados de muitas formas, fomentando uma concepção 
de Filosofia, conhecimento e arte racistas, o que só pode ser entendido, especialmente pela alusão de Kant ao uso da violência contra a população negra, com profunda indignação.

É importante ressaltar que nem todos os filósofos ocidentais compactuaram com esse ideal racional moderno. Filósofos como Nietzsche, Foucault, Deleuze \& Guattari, Derrida, Feyerabend, entre outros, produziram importantes estudos de crítica à razão universalista moderna. Porém, embora sejam exaustivamente estudados especialmente no Brasil, vemos que seu estudo serve ao comentarismo e não à ruptura deste paradigma. Suas críticas levam à produção de discípulos, o que contraria as próprias reflexões feitas por eles, reafirmando uma relação subalterna. Raramente nos estudos produzidos a partir desses autores vemos mudanças metodológicas, em geral seus estudos são lidos com o uso do próprio método que criticam. Suas críticas acabam sendo usadas para a produção de mais teorizações aos moldes modernos, isso explica porque as discussões desses trabalhos se voltam para a clareza de conceitos e não para um pensamento vivo sobre o mundo.

\section{O pensamento colonial hierárquico na compreensão dos saberes e da Filosofia}

O pensamento eurofalogocêntrico que permite dogmatizar saberes locais europeus, tem suas raízes num pensamento do tipo árvore, que foi associado por Descartes ao conhecimento. Em Princípios da Filosofia (1644), como uma resposta à ascensão de um novo modo de lidar com os problemas que vinha sendo desenvolvido por pesquisadores como Galileu e Kepler, Descartes repensa que papel deveria ter a Filosofia:

toda a filosofia é como uma árvore, cujas raízes são formadas pela metafísica, o tronco pela física e os ramos que saem deste tronco, constituem todas as outras ciências que, ao cabo, se reduzem a três principais: a medicina, a mecânica e a moral, entendendo eu por moral a mais elevada e mais perfeita, a que, pressupondo inteiro conhecimento das outras ciências, vem a ser o último grau da sabedoria. (DESCARTES, 1989, p.42)

$\mathrm{Na}$ perspectiva cartesiana, o campo do saber pode ser representado pelo modelo árvore de maneira que a base de todo o conhecimento se alicerçaria na metafísica, dando importante papel para a Filosofia. A física, que era a ciência de maior destaque neste cenário, representada pelo tronco, seria derivada da metafísica, e, portanto, da Filosofia; e as demais ciências como a medicina e a mecânica seriam os ramos, dentre os quais a moral receberia especial atenção. A árvore do conhecimento cartesiana é resultado de uma busca incessante do filósofo em estabelecer primordialmente um alicerce seguro para o edifício do conhecimento, buscando princípios indubitáveis para o saber, e, também, de estabelecer uma utilidade para a Filosofia nesse contexto. Nesse sentido, Descartes propõe um modelo hierárquico e abstrato para o conhecimento.

O pensamento arborescente hierarquizante é característico do saber dominante Ocidental e permeia a sociedade de diversos modos: "No Ocidente a árvore plantou-se nos corpos, ela endureceu e estratificou até os sexos. Nós perdemos o rizoma ou a erva" 
(DELEUZE; GUATTARI, 1995, p. 28). Para Deleuze e Guattari (1995, p. 28), "Muitas pessoas têm uma árvore plantada na cabeça, mas o próprio cérebro é muito mais uma erva do que uma árvore" porque seu funcionamento se dá por conexões não hierárquicas, se utiliza de contínuas ramificações não centralizadas (DELEUZE; GUATTARI, 1995, p. 24). Inclusive a compreensão da sexualidade foi profundamente permeada por esse modelo arborescente, o que fica evidente diante do sexismo ainda hoje muito presente socialmente. Porém, a principal influência desse pensamento está na compreensão da própria natureza do conhecimento que é associada à reprodução de representações baseadas num sistema hierárquico no qual os saberes dominantes são afirmados. A "acadêmica, psicanalista, filósofa, escritora e artista multidisciplinar (como melhor se define)" (KILOMBA, 2019, n.p.) Grada Kilomba nos ajuda a compreender como o pensamentoárvore está entranhado na mentalidade atual. Em exposição na Pinacoteca do Estado de São Paulo em setembro de 2019 , a artista se surpreendeu ao ver sua biografia reduzida à

[...] única estudante negra na universidade e que ganhou uma bolsa para ir para a Alemanha. [...] Como artista negra, todo o teu percurso desaparece muito rapidamente. E há um certo populismo em reduzir tua biografia a um roteiro quase de telenovela, uma coisa bem sensacionalista, que não explica quem tu és, nem a complexidade do teu trabalho. (KILOMBA, 2019, n.p.)

Isso é resultado da compreensão eurofalogocêntrica do conhecimento que só permite olhar o mundo e os sujeitos a partir de poucas categorias, de maneira que a complexidade da vida nunca é valorizada, mas apenas capitalizada visando corresponder aos parâmetros dominantes. Nas palavras de Kilomba:

Nós temos uma noção muito patriarcal e fálica do que é o conhecimento. Fazemos muitas coisas, mas há uma hierarquia: aquilo que está ligado à academia é o verdadeiro conhecimento e a verdadeira profissão. Depois, nós nos especializamos numa coisa, depois fazemos um mestrado, um doutorado... É uma coisa bem fálica que vai crescendo, crescendo, crescendo. Eu acho a coisa é muito mais cíclica, mais circular, em que nosso conhecimento atravessa muitas diferentes disciplinas e está em diálogo com diferentes formatos. [...] A Pinacoteca, que tem um acervo de arte brasileira composto maioritariamente por duas disciplinas clássicas, esculturas e pinturas, representa corpos que não são todos os corpos brasileiros. Portanto, há uma narrativa do que é o conhecimento, do que é a arte, e dos corpos, sexualidades e dos gêneros excluídos, e que cria categorias para desumanizar certos corpos e identificá-los como desviantes, inferiores, insubordinados, aqueles que não podem representar a nação. Essa é uma das dimensões do colonialismo, que é patriarcal, é homofóbico, é toda forma de opressão. (KILOMBA, 2019 , n.p.) 
Nesse sentido, o conhecimento escolarizado e acadêmico segue a estrutura patriarcal e fálica do acúmulo - como tudo no capitalismo - tratando o conhecimento numa lógica de propriedade privada sustentada por hierarquias. De diversas formas somos ensinados nos espaços de educação formal qual o padrão para o que se denomina "conhecimento". Kilomba cita como exemplo o acervo da Pinacoteca do Estado de São Paulo, no qual a partir da seleção de um determinado perfil de autores, obras e representações se cria uma narrativa que especifica quais saberes e corpos são válidos colocando no topo de todas as hierarquias válidas homens brancos europeus. Tais padrões constam em todas as dimensões da sociedade, se propagam especialmente através dos meios de comunicação, mas ganham seu status legítimo a partir do ensino formal e dos espaços de cultura. O que Kilomba sugere ao questionar essa lógica patriarcal do conhecimento é uma compreensão dos saberes de forma cíclica e não fragmentada que permeia diversas facetas e sujeitos, que não se restringe a disciplinas específicas nem a indivíduos isolados. Nesta perspectiva apresentada por Kilomba, o saber se reinventa continuamente fugindo da lógica da especialização e do acúmulo de saberes hierarquizados em graus de dificuldade e segmentados em categorias abstratas. $\mathrm{Na}$ escola desde cedo aprendemos que a nota é decorrente de nosso empenho individual, isso se repete na universidade especialmente no curso de Filosofia onde nos ensinam que o saber se produz sozinho no contato com os livros. Kilomba aponta para a compreensão do saber como um processo coletivo e transdisciplinar que se pauta em problemas e não em representações a serem reproduzidas, onde a segmentação não tem sentido em nenhuma de suas esferas.

A hierarquização do conhecimento estrutura todas as esferas da vida e do pensamento, como é possível observar no exemplo do próprio acervo da Pinacoteca do Estado de São Paulo, como citado por Kilomba. Para a pensadora a colonialidade tem três dimensões intrínsecas: "a marginalização de certos corpos e certas identidades; a capitalização da terra, da natureza, do ambiente; e a militarização das relações humanas", pois "A política do colonialismo é a política do medo. É criar o 'outro', criar corpos desviantes e dizer que eles são assustadores e terríveis e que nós temos que defender-nos deles com barreiras como passaportes e fronteiras" (KILOMBA, 2019 , n.p.). A narrativa eurofalogocêntrica encobre e, assim, produz corpos, sexualidades e gêneros excluídos, invisíveis, que são desumanizados por seus desvios e sua inferioridade forjada. E, para o controle social se efetivar se faz necessário o controle da natureza, para que os povos se tornem dependentes das classes dominantes impedindo sua subsistência autônoma.

Numa perspectiva hierárquica as diferenças são entendidas como desigualdades naturais e não em si mesmas. Na escola isto fica evidente quando refletimos sobre os processos de ensino e aprendizagem. A diferenças sempre é vista como um "erro" e o "certo" consiste na reprodução do padrão determinado pelo docente. Quando analisamos o ensino de Filosofia isto é ainda mais grave, pois no Brasil seus saberes hegemônicos estão totalmente alinhados à colonialidade. O ensino de Filosofia tradicional adotado na maioria dos contextos formais no Brasil se pauta num modelo de educação dominadora e baseada na colonialidade propagando a subalternidade diante dos problemas e um ideal de humanidade. Nesse modelo de ensino de Filosofia dominador o currículo é composto majoritariamente por 
homens brancos europeus, e às vezes somam-se a eles homens brancos norte-americanos, e a metodologia é baseada exclusivamente no comentarismo e na reprodução de filósofos tanto na formação universitária quanto no Ensino Médio, não lidando em nenhuma esfera com problemas. Tal contexto propaga uma ideologia subalterna que faz com que não nos vejamos como capazes de filosofar e anula a possibilidade de qualquer filosofia a partir do Brasil. Inclusive é comum ouvirmos nas universidades que não existem filósofos brasileiros, e muito menos filósofas - "mulheres não são racionais" -, isto faz com que quase a totalidade das pesquisas desenvolvidas na área se resumam a comentarismos de obras europeias.

Desse modo, passamos a entender os problemas de filósofos europeus e - e alguns poucos norte-americanos - como se fossem os nossos problemas cometendo o grande equívoco de aplicar suas soluções para nossos contextos, o que nos impede de ver quais são os nossos reais problemas e de pensá-los a partir de nossa própria realidade. Por meio de um ideal colonizado, o ensino de Filosofia no Brasil perpetua uma relação subalterna com os problemas, que é extremamente prejudicial diante de uma contexto com tantos desafios quanto o atual, até mesmo porque europeus e norte-americanos já deram vários exemplos na história de que não irão buscar soluções que nos beneficiem para o mundo em colapso ecológico que está por vir.

\section{Como decolonializar o ensino de Filosofia?}

Decolonializar diz respeito às tentativas de criar algo novo que transcenda a lógica da colonialidade ainda tão presente em nossa sociedade. Como explica Ballestrin em entrevista (2013, n.p.):

\footnotetext{
O giro decolonial procura responder às lógicas da colonialidade do poder, ser e saber, apostando em outras experiências políticas, vivências culturais, alternativas econômicas e produção do conhecimento obscurecidas, destruídas ou bloqueadas pelo ocidentalismo, eurocentrismo e liberalismo dominantes. Concebe a importância da interação entre teoria e prática, buscando dialogar com a gramática das lutas sociais, populares e subalternizadas dos povos que compuseram e compõem a invenção da ideia de América Latina.
}

Aqui cabe um importante esclarecimento: a adoção do termo "decolonial" decorre do fato de "descolonização" indicar a superação do colonialismo, algo que está longe de ocorrer. Para conceber um filosofar e ensino de Filosofia que esteja à altura da contemporaneidade acreditamos ser necessário questionar os pressupostos e categorias que nos assolam quanto à própria natureza do conhecimento. Como forma de decolonização, Kilomba tem como proposta (2019, n.p.) "criar instalações em que a audiência vem e não sabe o que é nem como é. Esse momento de confusão é descolonização. É quando começamos a questionar o que é o conhecimento, o que eu sei e o que eu não sei, e por que eu não sei e que relação isso tem com o ato de silenciar e invisibilizar". Todo saber tem um contexto, decolonializar 
o pensamento é refletir continuamente sobre os lugares de construção de conhecimento do outro e de nós mesmos. Por isso, é importante que sejam valorizadas as experiências das/dos estudantes e que o conhecimento seja entendido como algo que se vivencia e não como uma teoria que se reproduz mesmo sem qualquer conexão com a realidade vivida.

A Filosofia que acreditamos se aproxima do que o senegalês Souleymane Bachir Diagne (2019, n.p.) disse em entrevista na sua vinda ao Brasil em 2019 para participação no debate "Filosofia: Diálogos contemporâneos entre África e Ocidente":

\begin{abstract}
Ela sempre foi revolucionária, mesmo quando ela estava calma, tranquila e sem urrar. Porque, na verdade, a razão desse estado das coisas é simplesmente porque a filosofia é um processo que toma as coisas nas raízes, que traz a partir das raízes. A palavra para isso é processo radical. Quer dizer, no sentido de pegar as coisas nas raízes. Ela não se contenta em ter ideias simplistas, que infelizmente estão em curso hoje se olharmos a situação política atual. Nós vemos que muitos regimes autoritários desenvolvem ideias extremamente simplistas. Falamos de slogans com frases bem curtas, de afirmações etc, e a filosofia não funciona dessa forma. A filosofia nos lembra da complexidade do mundo e convida a todos a fazerem perguntas radicais, se perguntar, sobre a solidez dos argumentos que sustentam os fatos. Em outras palavras, a exigência da verdade, a exigência de examinar, que são duas coisas da essência da filosofia, não combinam com o slogan político que finge não precisar da verdade e dos fatos - e nós vivemos um momento de muitas ficções e fake news. E a filosofia é inimiga de um processo autoritário como esse, mesmo que ela não grite, mesmo se ela não tome posições aparentemente revolucionárias porque chama a uma revolta etc. O simples processo filosófico é revolucionário. (DIAGNE, 2019, n.p.)
\end{abstract}

A Filosofia a partir da diversidade de pensamentos e modos de vida possíveis aponta para a complexidade do mundo e não para a relativização do mesmo como a política atual simplista com suas fakenews tenta promover. Compreender diversos mundos possíveis permite o sonho, a utopia e pensar novos modos de viver que superem as dificuldades que o contexto vivenciado apresenta. No entanto, para isso, a Filosofia precisa pensar radicalmente, arrancar pelas raízes para conseguir ir além do mundo que está posto. Concordamos com Diagne que o filosofar consiste no movimento de expor o que está na raiz de qualquer pensamento recusando respostas e soluções simplistas.

Pensar uma Filosofia decolonial, nesse sentido, consiste em rejeitar o modus operandi da árvore do conhecimento, romper com as hierarquias, isto significa não encaixotar os saberes dos/das estudantes em categorias pré-estabelecidas nem os/as forçar a reproduzi-las reprimindo seu conhecimento próprio. E, no caso do ensino de Filosofia, área responsável por grande parte das ideologias dominantes, a decolonialidade implica num dever de radicalizar, isto é, arrancar pelas raízes, desvelar o que está escondido nos discursos colonizados que nos violentam cotidianamente. Significa olhar a vida para além da árvore, ver as raízes, a grama, a terra, os insetos, os fungos e as ervas que estabelecem relações intrínsecas e permitem a existência da árvore em simbiose. Isto é, ver a diferença em si mesma. 
Filosofar é o ato de pensar problemas, porém, em nossa concepção, acreditamos que esta não é uma atividade abstrata, mas consiste justamente em observar o mundo para entendê-lo, analisar o que o determina e projetar suas consequências. A partir da atividade de aprender com o mundo é possível adotar comportamentos mais responsáveis diante dele. Acreditamos em um filosofar que está para além da teoria, que significa entender o mundo para agir de forma consciente. Contudo, a primeira reflexão que fazemos para pensar um ensino de Filosofia à altura do nosso tempo é: para que estamos formando? 0 currículo tradicional tanto na Filosofia quanto em qualquer outra área em geral se pauta em um conteudismo que visa instrumentalizar estudantes para as sociedades do passado. Isto ocorre porque os/as docentes se baseiam apenas em suas formações e se empenham pouco ou quase nada em olhar para o presente. Como podemos formar estudantes para agirem no presente restringindo seu olhar apenas para o passado e ignorando completamente o futuro? Tal concepção não questiona criticamente a realidade, mas apenas promove ajustamento à ela - no caso ao passado - anulando qualquer possibilidade de transformação de si e do mundo. Nessa perspectiva, o que consideramos mais problemático é o fato de o conteúdo ser tratado como um fim em si mesmo e não como meio de intervenção na realidade.

Contudo, como decolonializar o ensino de Filosofia no Brasil? Primeiramente, é preciso romper com uma fragmentação entre pensamento e vida tão propagada pelo dualismo eurofalogocêntrico. Pensamento desconectado do cotidiano é alienação e não ajudará a lidar com os desafios da contemporaneidade. Nesse sentido, é preciso fomentar uma filosofia em ação no cotidiano escolar através do pensamento dos problemas que afetam os/as estudantes e as comunidades a que pertencem. Isto passa por elaborar um currículo a partir de problemas, o que não deveria ser difícil para os/as filósofos/as, pois isto permite conectar a escola com as diferentes demandas locais e regionais. Além do que é essencial que os currículos tenham uma boa margem de abertura na qual outros temas possam sempre serem inseridos de acordo com as necessidades, assim como a participação ativa da comunidade fará toda a diferença para um ensino de Filosofia em que os conteúdos não sejam fins em si mesmos, mas sim meios. Acreditamos que nenhuma outra área mais do que a Filosofia deveria ter maior facilidade em promover um currículo baseado em problemas. Com a concepção de currículo a partir de problemas, a Filosofia passa a ter um papel fundamental na educação como um todo para o mundo que está por vir, exatamente o contrário do que propaga a política atual que afirma a inutilidade da área.

\section{Considerações finais}

A história da Filosofia ocidental nos conta que filosofar é lidar com problemas. Considerando apenas a Filosofia ocidental em sua origem vemos que a tradição da antiguidade grega entendia o filosofar como algo relacionado aos problemas do cotidiano e que não era uma abstração total, mas que filosofar era um modo de vida, tinha a ver com os hábitos e não apenas com teorias. Porém, quando olhamos para a Filosofia no Brasil 
encontramos primordialmente comentários de livros, autores e conceitos europeus, mas raramente problemas, mais raramente ainda reflexões que falem sobre o Brasil. Na melhor das hipóteses vemos pesquisadores tentando encaixar teorias europeias para explicar a realidade brasileira.

Neste artigo, iniciamos apontando algumas contribuições da Filosofia ocidental hegemônica para a legitimação do pensamento colonial. A colonialidade ainda hoje é o principal parâmetro para o conhecimento na educação brasileira e no ensino de Filosofia, que em geral se pauta num currículo exclusivamente formado por homens brancos europeus. Como a Filosofia ocidental contribui para a inferiorização do pensamento que emerge em nosso território, entendemos que o ensino de Filosofia no Brasil tem a obrigação de atuar na sua desconstrução, expondo as raízes desse pensamento hierárquico que subjuga nossos potenciais. Isto passa por romper com a dualidade entre pensamento e vida e pensar um currículo a partir da experiência problemática com o mundo. Decolonializar o filosofar implica em ver o que está além da árvore do conhecimento, entender as diferenças como potencial e todos os sujeitos envolvidos como capazes de pensar por si mesmos. Somente assim, pensando coletivamente, o ensino de Filosofia poderá contribuir para os desafios do mundo contemporâneo.

\section{Referências}

BALLESTRIN, Luciana. Para transcender a colonialidade. [Entrevista concedida a] Luciano Gallas e Ricardo Machado. IHU - Revista do Instituto Humanitas Unisinos. Edição 431, 04 novembro 2013. Disponível em: http://www.ihuonline.unisinos.br/artigo/5258-lucianaballestrin. Acesso em: 03 de maio de 2020.

DELEUZE, Gilles \& GUATTARI, Félix. Mil platôs: capitalismo e esquizofrenia, vol. 1. São Paulo: Ed. 34: 1995.

DERRIDA, Jacques. Margens da Filosofia. Trad.: Joaquim Torres Costa. São Paulo: Editora Papirus, 1991.

DESCARTES, René. Princípios da Filosofia. Lisboa: Guimarães SC ${ }^{a}$ Editores, 1989.

DIAGNE, Souleymane Bachir. "A filosofia é inimiga do autoritarismo", diz senegalês Souleymane Bachir Diagne. [Entrevista concedida a] Marília Moreira. Correio 24 horas. Salvador, 15 agost, 2019. Disponível em: https://www.correio24horas.com.br/noticia/nid/afilosofia-e-inimiga-do-autoritarismo-diz-senegales-souleymane-bachir-diagne/. Acesso em: 16 de ago. 2019.

HEGEL, George W. F. Lecciones sobre la filosofía de la historia universal. Madrid: Alianza Editorial, 1982.

HUME, David. Ensaios Morais, Políticos e Literários. Tradução de. Luciano Trigo. Rio de Janeiro: Topbooks, 2004.

KANT, Immanuel. Observações sobre o sentimento do belo e do sublime; Ensaio sobre as doenças mentais. Trad.: Vinícius de Figueiredo. Campinas, SP: Papirus, 1993. 
KILOMBA, Grada. Grada Kilomba: "O colonialismo é a política do medo. É criar corpos desviantes e dizer que nós temos que nos defender deles". Entrevista concedida a Joana Oliveira. El país. São Paulo, 12 set, 2019. Disponível em: https://brasil.elpais.com/ brasil/2019/08/19/cultura/1566230138_634355.html?\%3Fssm=FB_Acesso em: 02 de setembro de 2019.

QUIJANO, Aníbal. Colonialidad y modernidad/racionalidad. Perú Indígena, 13 (29), 1992, p. 11-20.

QUIJANO, Aníbal. Colonialidade do poder, eurocentrismo e América Latina. In: A colonialidade do saber: eurocentrismo e ciências sociais. LANDER, Edgardo (org). Buenos Aires: Conselho Latino-americano de Ciências Sociais - CLACSO, 2005.

QUIJANO, Aníbal. Colonialidade, poder, globalização e democracia. In: Novos Rumos, São Paulo, ano 17, n. 37, p. 4-28, 2002.

QUIJANO, Aníbal. Colonialidad del Poder, Cultura y Conocimiento en América Latina. In: Anuário Mariateguiano. Lima: Amatua, v. 9, n. 9, 1997.

ROUANET, Sergio Paulo. O mito do bom selvagem. Disponível em: https://www. artepensamento.com.br/item/o-mito-do-bom-selvagem/. (1999) Acesso em: 20 de set. de 2019.

\section{Notas}

${ }^{1}$ É importante lembrar que existem diversas formas de organizar a história do pensamento filosófico, por isso, os livros de diferentes países ou historiadores mostram diferenças enormes em suas estruturas.

\section{Correspondência}

Amanda Veloso Garcia - Rua José Breves, 550, Centro, 27197-000, Pinheiral, Rio de Janeiro, Brasil.

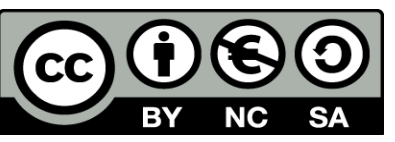

This work is licensed under a Creative Commons Attribution-NonCommercial 4.0 International (CC BY-NC 4.0) 